\title{
Prática enquanto componente curricular: um relato de experiência
}

\author{
Andressa Falcade, Aureo V. D. A. Rocha, Cleitom J. Richter, Juliani Natalia dos Santos, \\ Lucas M. Dornelles, Stefano L. Barbosa, \\ ${ }^{1}$ Instituto Federal de Educação, Ciência e Tecnologia Farroupilha (IFFar - Campus Santo \\ Augusto) - Santo Augusto - RS - Brasil. \\ \{andressafalcade, vinnyciusd, dorlucas\} egmail.com, \{juliani.santos, \\ cleitom.richter\} @iffarroupilha.edu.br, stefanolenz@hotmail.com
}

\begin{abstract}
One of the roles of computer science teachers in basic education is to promote greater integration between subject content and technology. For this reason, the academic training course of this professional needs to be designed to support the processes of creating resources that help other teachers in the dynamics of teaching. with this in mind, it was proposed to the students of the discipline of Computing Teaching Practice, of the fifth semester of the Degree in Computer Science of the IFFar Campus Santo Augusto, the production of learning objects. The application of this study was considered positive by students who requested more moments of integration between theory and practice in the course.
\end{abstract}

Resumo. Um dos papéis do docente de informática na educação básica é o de promover maior integração entre os conteúdos disciplinares e a tecnologia. Por esse motivo, o curso de formação acadêmica desse profissional precisa ser pensado para apoiar os processos de criação de recursos que possam auxiliar, também, outros professores na dinâmica do ensinar. Pensando nisso, foi proposto aos estudantes da disciplina de Prática do Ensino da Computação, do quinto semestre do curso de Licenciatura em Computação do IFFar Campus Santo Augusto a produção de objetos de aprendizagem. A aplicação deste estudo foi considerada positiva pelos estudantes que solicitaram mais momentos de integração entre teoria e prática no curso.

\section{Introdução}

Com o avanço das tecnologias digitais no ambiente escolar, tornou-se necessário qualificar os professores para o uso e a produção de recursos didáticos adequados aos diferentes processos de ensino e aprendizagem, principalmente no que tange aos recursos educacionais digitais que permitem estratégias de dinamização do conteúdo e do método proposto para as aulas. Nesse meio está o licenciado em computação que adentra o espaço escolar com o propósito de fomentar a integração das tecnologias com todas as demais disciplinas curriculares através da produção de alternativas de trabalho que vão além da pesquisa na Internet. Para que esse profissional licenciado esteja preparado para ocupar esse papel, é fundamental que em sua formação seja incentivado a produzir materiais didáticos que facilitem sua prática docente.

Pensando nessa formação, o curso de Licenciatura em Computação do Instituto Federal Farroupilha - Campus Santo Augusto - oferta oito disciplinas denominadas de Prática do Ensino da Computação, a fim de "proporcionar experiências de articulação de conhecimentos construídos ao longo do curso em situações de prática docente" [BRASIL 2014 p.32] e, além 
VIII Congresso Brasileiro de Informática na Educação (CBIE 2019)

Anais dos Workshops do VIII Congresso Brasileiro de Informática na Educação (WCBIE 2019)

disso, fornecer aos estudantes a prática no âmbito do "desenvolvimento de projetos, metodologias e materiais didáticos próprios do exercício da docência" [BRASIL 2014 p.32].

Essa articulação, prevista no Projeto Pedagógico do Curso, ocorre entre as disciplinas do semestre letivo, sendo que cada semestre passa por um 'fio condutor' definido por Cambraia e Moraes (2015) como uma forma de gerar um movimento contínuo no processo formativo dos estudantes. Na proposta definida por Cambraia e Moraes (2015), o primeiro semestre letivo baseia-se em um diagnóstico do contexto global da computação na sociedade, primando pela análise dos assuntos pesquisados na área de informática da educação. O segundo semestre busca verificar a presença de ambientes que promovam a informática dentro das escolas em âmbito regional e local. Já o terceiro semestre aborda as políticas públicas de inclusão digital presentes nessas escolas.

A partir do quarto semestre, os estudantes são submetidos a reflexões sobre o uso da tecnologia como ferramenta de ensino, seguindo essa reflexão no quinto e sexto semestres através da produção de propostas pedagógicas para o ensino da computação. Nos dois últimos semestres, é realizada a interação do futuro docente com o seu campo profissional, proporcionando a experiência do diálogo e da sistematização da prática pedagógica, bem como da relação entre o Instituto de Educação e a escola [CAMBRAIA e MORAES 2015].

Frente a essa dinâmica do curso, este artigo busca apresentar a integração curricular ocorrida na disciplina de Prática do Ensino da Computação V (PEC V), durante o primeiro semestre letivo de 2019. Essa PEC, presente no quinto semestre, propôs-se a articular, junto aos acadêmicos, a produção de um Objeto de Aprendizagem (OA) que tivesse por temática o ensino de algum conteúdo computacional, uma vez que os estudantes já possuem experiência dentro das técnicas e temáticas da informática. Nesse momento, a integração curricular da proposta ficou a cargo das disciplinas de Programação Web, Diversidade e Educação Inclusiva e Interação Humano-Computador, visando proporcionar melhorias no aprendizado voltado à realidade escolar.

Ao todo, foram cinco estudantes envolvidos com esse projeto, sendo eles divididos em dois grupos (Grupo A, com dois participantes, e Grupo B, com três participantes). Desses grupos, apenas o Grupo B conseguiu concluir o OA e, por esse motivo, somente os seus resultados serão expostos neste artigo. $\mathrm{O}$ grupo A não concluiu a proposta em virtude da desistência dos seus componentes. O restante deste estudo está dividido da seguinte forma: na segunda seção será discutida a integração curricular na formação do profissional do licenciado em computação; na terceira seção são expostos alguns conceitos sobre objetos de aprendizagem; na quarta seção são apresentados alguns trabalhos relacionados a esta pesquisa; na quinta seção será demonstrado o método empregado na pesquisa; na sexta seção serão expostos os resultados obtidos no desenvolvimento do OA; a sétima seção é responsável pela reflexão sobre a prática desenvolvida e sobre a integração curricular proposta na PEC V.

\section{Integração curricular na formação do Licenciando em Computação}

A integração curricular faz parte do entrelaçamento entre os componentes curriculares que compõem o curso - aqui representados pelas disciplinas supracitadas, assim a proposta da PEC $\mathrm{V}$ esteve voltada a uma atividade prática envolvendo a criação de um $\mathrm{OA}$, bem como a realização de uma análise reflexiva acerca do processo de construção do objeto. Trata-se de um movimento que busca, além da prática, realizar a integração curricular e exercitar a pesquisa docente desde a formação inicial.

No que se refere ao desenvolvimento da prática, vale ressaltar que essa atividade esteve vinculada ao preceito legal disposto nas Resoluções $\mathrm{CNE} / \mathrm{CP} \mathrm{n}^{\circ} 01$ e 02/2002 que determinam que os cursos de licenciatura organizem quatrocentas horas de atividades práticas vivenciadas 
VIII Congresso Brasileiro de Informática na Educação (CBIE 2019)

Anais dos Workshops do VIII Congresso Brasileiro de Informática na Educação (WCBIE 2019)

ao longo do curso. Em consonância com essa obrigatoriedade legal, o PPC do curso de Licenciatura em Computação do IFFar - Campus Santo Augusto, deixa explícito que será fomentada uma cultura de integração curricular articulada na Prática enquanto Componente Curricular $(\mathrm{PeCC})$ através de oito componentes curriculares denominados de Prática do Ensino da Computação (PEC) [BRASIL 2014].

Todavia, embora a organização da PeCC em componentes curriculares possa parecer uma solução compartimentada, incoerente à proposta de integração curricular, é importante salientar que tais componentes têm a finalidade de servir como eixos norteadores da prática profissional realizada em cada semestre, pois devem "articular o conhecimento de no mínimo duas disciplinas do semestre, pertencentes, preferencialmente, a núcleos distintos do currículo" [BRASIL 2014 p.32].

Nesse caso, faz-se necessário promover a discussão sobre o conceito de integração curricular trabalhado no curso, para que fique clara a intencionalidade de cada disciplina ofertada no decorrer da formação do licenciado. Desse modo, pode-se ponderar que a integração curricular vai ao encontro do que propõe Pacheco (2000), ao destacar que ela (a integração curricular) existe no sentido de melhorar o aprendizado dos estudantes, visto que busca romper com a visão simplista das disciplinas compartimentadas em seu saber científico.

Assim, segundo Felício (2015), a integração curricular pressupõe a necessidade de propiciar a confluência entre os diferentes conhecimentos trabalhados nas disciplinas sem fragmentá-los. Trata-se de um movimento em prol da formação dos estudantes que visa proporcionar uma visão ampla entre o saber e o fazer e o impacto disso na sua formação.

Espera-se que o avanço nessa discussão promova nos estudantes a compreensão de que a pesquisa realizada na PEC e a produção de um OA é uma atividade prática essencialmente norteada por fundamentos teóricos, pois "a unidade entre teoria e prática é condição para compreender o currículo como um instrumento que não se limita a uma atividade teórica irrealizável, ou a uma atividade prática sem conexão com a atividade teórica" [BARBOZA e FELICIO 2018 p.29].

Diante disso, para promover a integração curricular desejada na PEC, outras três disciplinas fizeram parte do projeto: Interface Humano-Computador (IHC), Diversidade e Educação Inclusiva (DEI) e Programação Web. Cada uma participando com atividades específicas e complementares durante o desenvolvimento do OA. Desse modo, a disciplina de IHC auxiliou na padronização das telas, botões e cores utilizados para o projeto, a Programação Web na construção de páginas web, fazendo com que ficassem dinâmicas e adequadas aos diferentes perfis de usuários, e a DEI auxiliou no suporte a aspectos relacionados à utilização do objeto por usuários com necessidades especiais.

\section{Objetos de Aprendizagem}

Com o avanço das tecnologias e da busca pela inclusão digital nas escolas, tem-se observado um aumento gradativo de recursos educacionais digitais para o ensino de diferentes conteúos. Entre esses recursos estão os OA "que surgiram como forma de organizar e estruturar matériais educacionais digitais" [TAROUCO et al. 2006 p.1].

Para Wiley (2000, p.7), um objeto de aprendizagem pode ser definido como "qualquer recurso digital que pode ser reusado para apoiar a aprendizagem". Silveira e Carneiro complementam essa definição denominando como objetos de aprendizagem "quaisquer materiais eletrônicos [...], desde que tragam informações destinadas à construção do conhecimento (conteúdo autocontido), explicitem seus objetivos pedagógicos e [...] possam ser reutilizados e recombinados com outros objetos de aprendizagem" (2014, p.5). Entre esses 
VIII Congresso Brasileiro de Informática na Educação (CBIE 2019)

Anais dos Workshops do VIII Congresso Brasileiro de Informática na Educação (WCBIE 2019)

materiais eletrônicos podem ser citados os vídeos, as imagens, as animações e/ ou simulações, bem como as páginas web [SILVEIRA e CARNEIRO 2014].

A partir da definição de OA e da integração curricular proposta pela PEC V, foi solicitado aos estudantes o desenvolvimento de um OA em plataforma web com características de acessibilidade, isso alinhado às disciplinas envolvidas nessa proposta - Programação Web, Diversidade e Educação Inclusiva e Interação Humano-Computador. Da primeira disciplina considera-se a plataforma de desenvolvimento do $\mathrm{OA}$ e das últimas a adaptação para necessidades especiais.

\section{Trabalhos relacionados}

Para o desenvolvimento do presente escrito, foi realizada uma pesquisa a fim de analisar o que vem sendo trabalhado com o tema integração curricular nos cursos de Licenciatura em Computação. Assim, para essa pesquisa foram utilizadas as palavras-chave "integração curricular, "prática enquanto componente curricular" e "licenciatura em computação", a fim de encontrar outros relatos de experiência que retratem esse componente dentro das licenciaturas.

A partir da pesquisa foram encontrados apenas 5 trabalhos com esse viés, contudo nenhum deles apresentou uma aplicação da prática enquanto componente curricular dentro de um curso de licenciatura. Destes cinco trabalhos, um deles apresentou discussões sobre as práticas do estágio supervisionado [JEFFREY et al. 2016], e quatro fizeram alusões especificamente sobre o conceito de PeCC e a sua presença/ausência nos projetos pedagógicos dos cursos de licenciatura [CAMBRAIA e BENVENUTTI 2017]; [CAMBRAIA 2017]; [CAMBRAIA e ZANON 2018]; [ANDRADE 2019].

A pesquisa realizada nos veículos de informação e comunicação permite constatar a pouca publicização das aplicações de projetos de PeCC nos cursos de licenciatura, demonstrando a relevância deste estudo no que diz respeito à exposição de uma proposta que traz à tona os resultados obtidos em um projeto interdisciplinar. Nesse sentido a realização deste trabalho buscou conduzir uma prática integradora em atenção ao que propõe o projeto pedagógico do curso.

\section{Método da Pesquisa}

A proposta deste estudo visa apresentar o relato de experiência de uma integração curricular no quinto semestre do curso de Licenciatura em Computação do Instituto Federal Farroupilha Campus Santo Augusto, dentro da disciplina de PEC V, a qual tinha por objetivo oferecer aos acadêmicos do curso experiências de cunho prático e teórico com vistas à formação plena da identidade docente, sendo essa experiência alcançada através da integração das disciplinas de Diversidade e Educação Inclusiva, Interação Humano-Computador e Programação Web, sendo a PEC V organizadora dessa integração.

A prática desenvolvida na PEC V buscou incutir nos estudantes do curso a produção de OA para o ensino da computação a fim de fomentar a autoria docente junto aos futuros profissionais. Além disso, possibilitou a contextualização do licenciado em computação com os conhecimentos adquiridos durante o curso, bem como com as práticas originadas no ambiente profissional no qual o estudante será inserido com o fim da graduação.

Ocorrido no primeiro semestre de 2019, este estudo teve a duração de 50 horas subdivididas no decorrer do semestre com encontros de 4 horas presenciais, uma vez por semana, além de momentos a distância para o desenvolvimento do OA. Nesses encontros, os estudantes foram submetidos a leituras sobre produção de OA [SILVEIRA e CARNEIRO 2014]; Design Instrucional e Matriz de Atividade [FILATRO 2008], Acessibilidade na Web 
VIII Congresso Brasileiro de Informática na Educação (CBIE 2019)

Anais dos Workshops do VIII Congresso Brasileiro de Informática na Educação (WCBIE 2019)

[BRASIL 2004]; e Carga Cognitiva de Trabalho [SWELLER et al. 1998], [MAYER 2002]. Essas leituras buscavam uma reflexão por parte dos futuros licenciados com relação ao esforço dispensado pelo estudante na utilização de recursos educacionais digitais, bem como apresentar características de acessibilidade que poderiam ser aplicadas no objeto a ser desenvolvido, buscando maior abrangência na utilização desse.

A partir das leituras, a turma participante, formada por 5 estudantes, dividiu-se em dois grupos (A e B) para o desenvolvimento de um OA que seria considerado para a avaliação na disciplina de PEC V. Esses estudantes tiveram autonomia na escolha da temática de ensino e utilizaram as aulas da PEC V para criar o seu produto, sendo que as disciplinas envolvidas proporcionaram momentos de discussão sobre os conceitos relacionados ao desenvolvimento do produto.

Ao final do semestre os estudantes realizaram uma apresentação para todos os estudantes do curso demonstrando os resultados de sua produção, bem como as suas percepções quanto ao projeto e quanto à integração curricular. Na próxima seção, será explorado esse desenvolvimento e as reflexões realizadas pelos estudantes no decorrer da aplicação deste trabalho.

\section{Objeto de Aprendizagem para o Ensino da História da Computação.}

Tendo em vista os objetivos da PEC V, optou-se pela construção de um objeto de aprendizagem que permitisse um passeio pela história da computação desde a criação das primeiras máquinas usadas para cálculos matemáticos, as quais são utilizadas até os dias atuais, quando a computação é a base de todos os aparelhos eletrônicos.

Pensando na integração curricular com a disciplina de Programação Web o OA foi construído em ambiente off-line, através do uso das linguagens de marcação HTML e CSS para a estruturação básica da página, e online, com o uso da linguagem de programação PHP, "amplamente utilizada por desenvolvedores ao redor de todo o mundo para a construção de uma série de aplicações, a exemplo de websites dinâmicos, pois permite a interação com o usuário por meio de links, formulários e parâmetros de URL" [SOUZA 2018 p.6].

A fim de também atender à proposta de integração curricular com as disciplinas de IHC e Diversidade e Educação Inclusiva, foram respeitados alguns aspectos que permitissem a acessibilidade do objeto a alunos com deficiência visual a partir do uso de um leitor de tela. Essa adaptação ocorre diretamente sobre o código fonte da página a partir de uma descrição após a inserção da imagem, como pode ser visto na Figura 1.

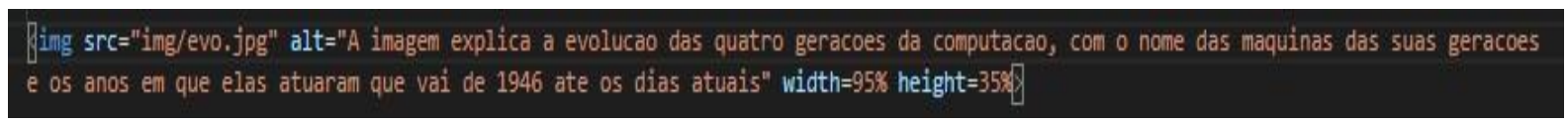

Figura 1. Código HTML que descreve a imagem inicial do OA.

Como pode ser visto na Figura 1, a descrição de imagens diretamente no código fonte ocorre através do atributo "alt" logo após a definição da imagem que será exposta. Essa descrição será "lida" pelo programa leitor de tela quando o usuário passar por ela. A acessibilidade do OA foi um elemento articulador da PEC V, uma vez que todas as disciplinas envolvidas com o projeto abordam essa temática em pelo menos um momento durante o semestre.

Na disciplina de Diversidade e Educação Inclusiva, a acessibilidade é tratada a partir das diferenças entre as pessoas, já em Interação Humano-Computador, são estudadas as diferentes aplicações de acessibilidade em interfaces computacionais, enquanto na Programação Web, são aplicados os conceitos de acessibilidade no desenvolvimento de 
VIII Congresso Brasileiro de Informática na Educação (CBIE 2019)

Anais dos Workshops do VIII Congresso Brasileiro de Informática na Educação (WCBIE 2019)

sistemas Web. Segundo o Decreto Federal n ${ }^{\circ}$ 5.296/2004, no artigo $8^{\circ}$, I, a acessibilidade é a segurança e autonomia dada à pessoa com deficiência para usar "dos espaços, mobiliários e equipamentos urbanos, das edificações, dos serviços de transporte e dos dispositivos, sistemas e meios de comunicação e informação" [BRASIL 2004]. Essa definição, dada pela legislação brasileira, demonstra a importância de se pensar a diferença de acesso à sistemas de informação e comunicação, principalmente aqueles voltados a aprendizagem.

Além da acessibilidade os estudantes buscaram uma maior diversidade de apresentação do conteúdo através da divisão do OA em quatro páginas distintas: Inicio, Conteúdos, Recursos e Quiz. Essas páginas foram criadas a fim de melhorar a movimentação dos usuários pelo objeto (Figura 2).

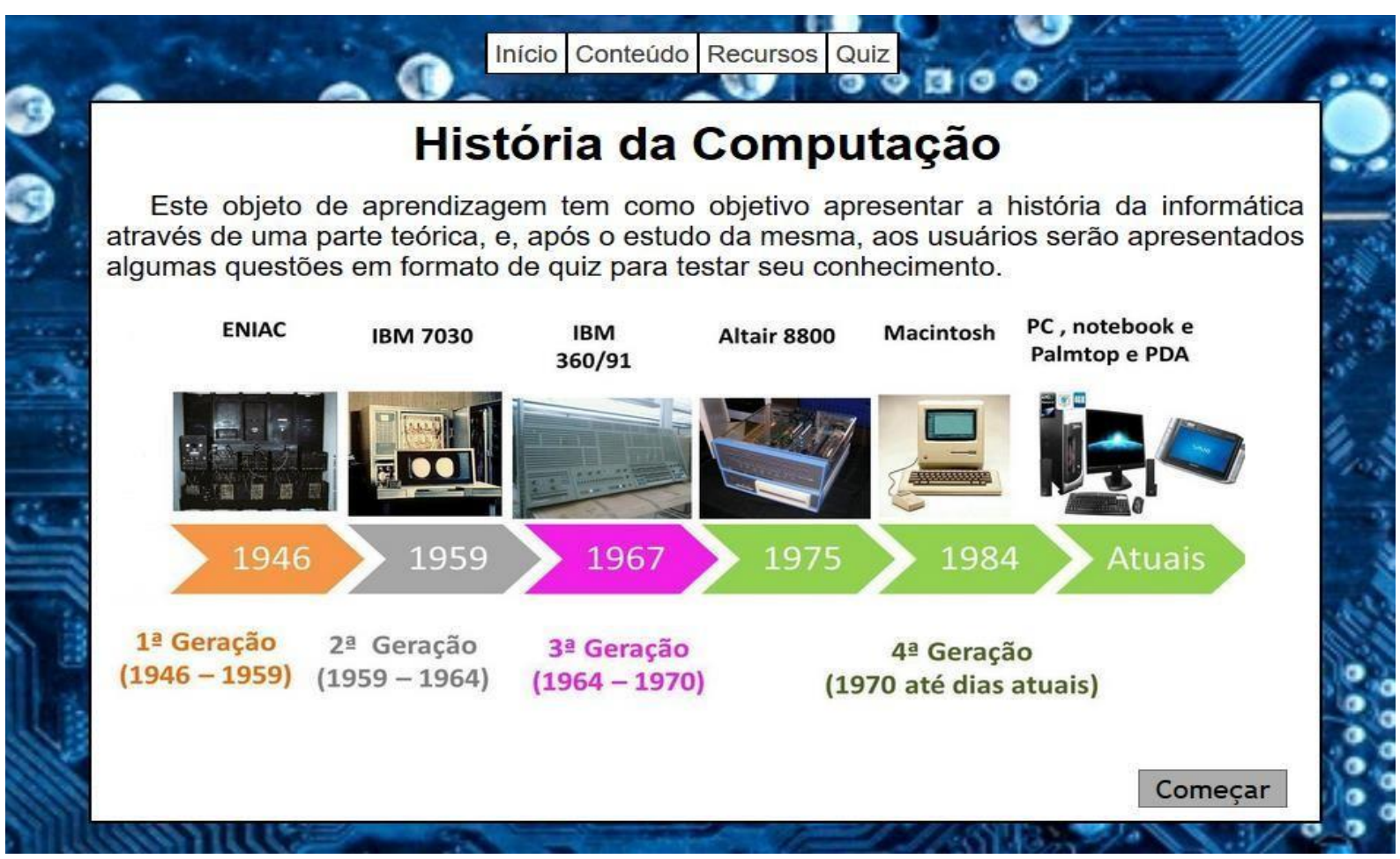

Figura 2. Página inicial do OA.

Como pode ser visto na Figura 2, a página inicial aborda o tema que será tratado durante o percurso no OA. É possível ao usuário percorrer o objeto através de botões localizados no final de cada página de conteúdo que fornece um caminho lógico de estudo. Outra possibilidade de percorrer essas páginas é através do menu conteúdo, onde foram disponibilizados atalhos para cada uma das gerações dos computadores. Já na página de recursos foi adicionado um vídeo sobre o assunto abordado, sendo este construído pelos estudantes através da ferramenta Movie Maker, a fim de dinamizar o passeio pelo conteúdo. O vídeo mostra brevemente a evolução dos computadores desde a primeira geração até os dias atuais.

A página Quiz fornece a possibilidade de testagem de conhecimentos. O usuário poderá responder a oito questões fechadas com quatro alternativas de resposta cada uma, sobre as informações presentes na história dos computadores. Após o preenchimento de todas as questões, é possível conferir as respostas corretas através do botão submeter na parte inferior da tela. Durante o aprimoramento desse feedback, os estudantes sentiram algumas dificuldades em apresentar na interface as respostas corretas e incorretas, marcadas pelos usuários. Primeiramente os desenvolvedores chegaram a cogitar o uso da Linguagem Java Script para a programação do feedback, porém ela foi abandonada devido à possibilidade de as questões marcadas serem destacadas através da Linguagem HTML, já utilizada no restante do OA. 
VIII Congresso Brasileiro de Informática na Educação (CBIE 2019)

Anais dos Workshops do VIII Congresso Brasileiro de Informática na Educação (WCBIE 2019)

Como pode ser visto na Figura 3, todas as respostas recebem pelo menos um feedback: de resposta correta. Quando o usuário marcar alguma resposta de forma incorreta o OA fornecerá duas informações, uma delas mostrando a resposta correta e outra mostrando a alternativa marcada.

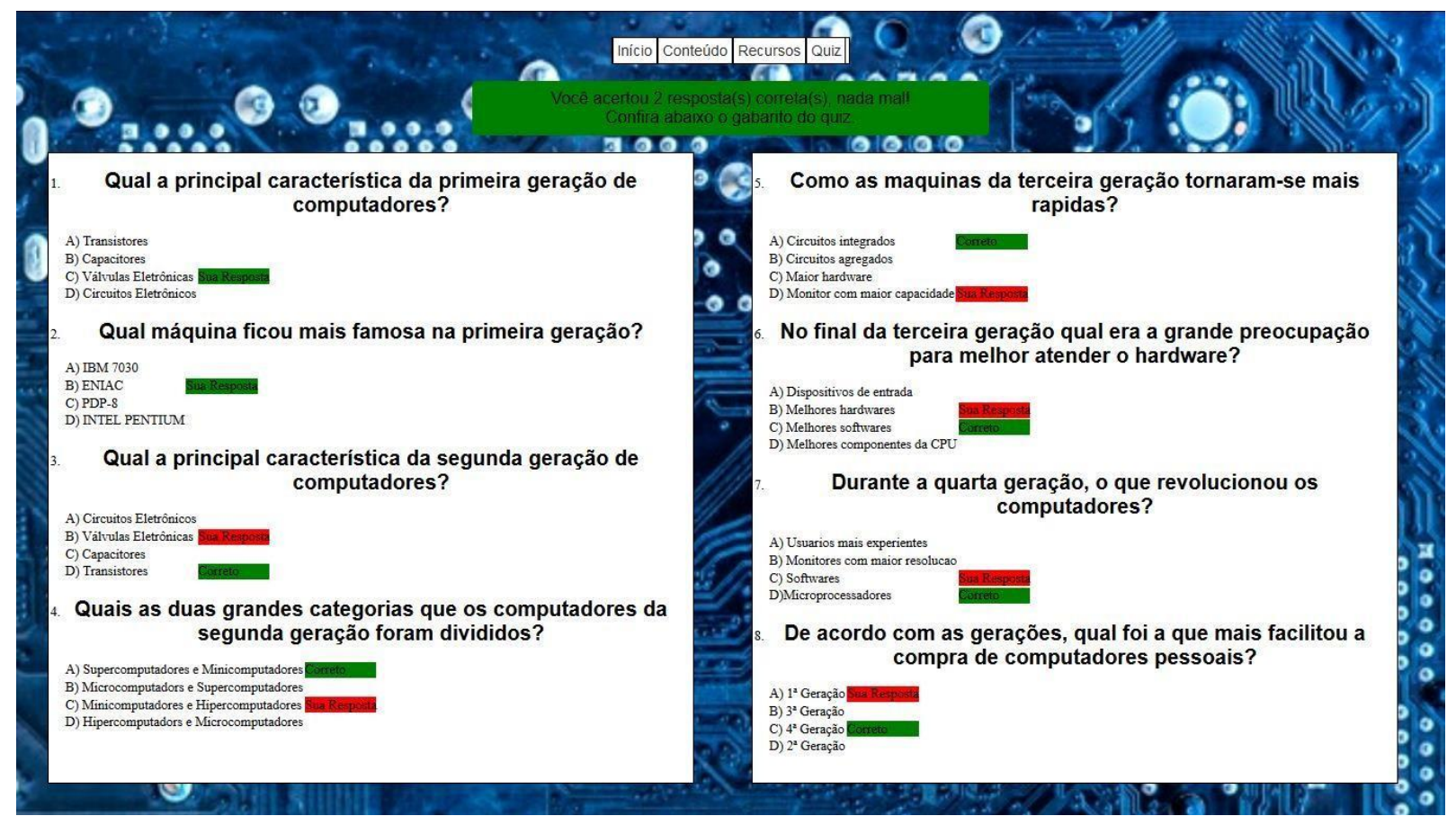

Figura 3. Feedback gerado pelo OA no Quiz.

Para Dose (2017, p.1568), os "retornos das atividades propostas [...] são relevantes para a construção da autonomia" do estudante, bem como favorecer a sua aprendizagem em ambientes digitais nos quais o professor não está presente. Para a autora, esse feedback permite ao estudante "avaliar se a sua linha de estudo está correta, ou que precisa ser reajustada, se redirecionando para a pesquisa e aprendizados esperados, a fim de que, diante de outras avaliações, o seu desempenho seja cada vez melhor" [DOSE 2017 p.1568]. Após a realização do quiz é possível desmarcar as alternativas através do botão "Limpar Respostas", para que seja realizada uma nova tentativa. Dessa maneira, o estudante que utilizar o OA, poderá realizar o quiz quantas vezes considerar necessário.

A geração dos computadores foi escolhida como temática do OA desenvolvido uma vez que é importante conhecer a origem dessa tecnologia antes de ver para onde ela está sendo direcionada. O objetivo do OA com essa temática é levar aos jovens estudantes um pouco da história que eles não puderam acompanhar, visto que nasceram depois desses primeiros passos da computação no mundo.

\section{Apresentação da PEC V}

Com o final do semestre e a finalização do OA, os participantes deste estudo realizaram uma apresentação para os demais estudantes de Licenciatura em Computação do IFFar - Campus Santo Augusto, sendo essa uma parte importante do método das PeCC, pois permite a exposição dos resultados de cada um dos semestres do curso.

Nesse momento os estudantes tiveram a oportunidade de retomar sua trajetória dentro da PEC V e refletir sobre a integração curricular desenvolvida no primeiro semestre de 2019, mostrando o objeto desenvolvido e todas as suas funcionalidades, especificidades e objetivos pedagógicos. Nessa mesma oportunidade, os estudantes apontaram a importância da produção 
VIII Congresso Brasileiro de Informática na Educação (CBIE 2019)

Anais dos Workshops do VIII Congresso Brasileiro de Informática na Educação (WCBIE 2019)

de recursos educacionais para sua formação profissional e solicitaram mais momentos desse tipo durante o decorrer do curso. Para os estudantes que participaram deste projeto, a PEC V proporcionou a união entre a teoria e a prática, bem como os motivou a buscar conhecimentos que eles ainda não possuíam.

Um dos estudantes destacou que sentiu na proposta da PEC V um desafio no que diz respeito à aprendizagem do estudante que iria usar o que eles estavam produzindo, pois eles ainda não haviam pensado a aprendizagem em ambientes eletrônicos. Apontaram também, as dúvidas com relação à escrita dos códigos em HTML, CSS e PHP que transformam as ideias em produto, contudo mostraram que as dúvidas foram sanadas com os professores que os ajudaram a aliar teoria e prática no desenvolvimento do $\mathrm{OA}$.

Devido aos integrantes do grupo não serem todos da mesma cidade o trabalho foi desenvolvido em sala, durante as aulas da PEC V, e através do Google Drive, de forma que todos os participantes puderam estar atualizados das alterações realizadas.

Em conversa com os estudantes, após a apresentação final, foi possível analisar a metodologia utilizada na organização da disciplina de PEC V. Percebeu-se que, apesar de a disciplina promover a discussão de elementos que os professores consideraram importantes para o desenvolvimento desta atividade, como Matriz de Atividade, Design Instrucional, Teoria da Carga Cognitiva e Teoria Cognitiva da Aprendizagem Multimídia, apenas as discussões sobre produção de OA e Acessibilidade na Web foram realmente considerados no momento de construção dos produtos pelos estudantes. Acredita-se que essa característica se deu devido ao viés da produção dentro da proposta, uma vez que os alunos não observaram outras questões senão aquelas estritamente ligadas à mecânica do desenvolvimento.

Como elemento pontual, a autonomia para o desenvolvimento do OA foi considerada negativa pelos estudantes, porque, segundo eles, a eficácia da autonomia é proporcional ao nível de organização na realização das tarefas e no cumprimento dos prazos estipulados. Para os estudantes, houve dificuldades de organização no decorrer do semestre e, segundo eles, os resultados precisam ser alcançados dentro da disciplina de PEC V através de exigências pontuais solicitadas em cada aula, bem como a organização pelo professor dos momentos não presenciais para a geração de resultados mais satisfatórios.

Por outro lado, os alunos apontaram que essa atividade foi positiva, visto que os motivou a produzir mais recursos, que poderiam ser usados posteriormente nas experiências futuras em sala de aula. Além disso, a atividade os fez reconhecer a importância da acessibilidade em interfaces, sendo elas desenvolvidas exclusivamente para o aprendizado ou não. Observando os resultados obtidos tanto de produção, como de integração curricular, percebe-se que a proposta da PEC V de integrar os conhecimentos teóricos e práticos do curso de Licenciatura em Computação conseguiu alcançar o seu objetivo, levando os estudantes a constituírem-se como autores de seus próprios recursos através da aliança entre informática e educação.

\section{Considerações Finais}

A integração curricular com vistas a proporcionar espaços de autoria docente dentro do curso de Licenciatura em Computação do IFFar - Campus Santo Augusto pode ser alcançada dentro de cada semestre através de projetos desenvolvidos nas disciplinas de Prática do Ensino da Computação.

Neste artigo foram expostos a ideia, o método, os resultados e as reflexões originadas da aplicação do projeto da PEC V, presente no quinto semestre do curso e desenvolvida no primeiro semestre do corrente ano. A turma participante contava com cinco estudantes que foram divididos em dois grupos (A e B) no início do período letivo, contudo apenas um dos 
VIII Congresso Brasileiro de Informática na Educação (CBIE 2019)

Anais dos Workshops do VIII Congresso Brasileiro de Informática na Educação (WCBIE 2019)

grupos, com três estudantes, conseguiu chegar ao final com um produto. A ideia desse projeto era fomentar a autoria docente através da produção de um OA para o ensino da computação.

Envolveram-se nesse projeto as disciplinas de Diversidade e Educação Inclusiva e Interação Humano-Computador e Programação $\mathrm{Web}$, onde as duas primeiras discutiram a importância da acessibilidade de interfaces para as diferentes necessidades dos estudantes e a última auxiliou os mesmos no desenvolvimento prático do objeto.

A totalidade dos conceitos abordados nas diferentes disciplinas não foram aplicados na produção do Objeto de Aprendizagem. Isso ocorreu devido à necessidade de amadurecimento da ideia e interligação entre o conceito e a sua aplicabilidade na prática. Cabe ressaltar que muito dos momentos favoráveis à autonomia docente tais como, os momentos não presenciais, não foram aproveitados pelos estudantes.

A partir do exposto, considera-se que a extensão do tempo de execução do projeto pode gerar resultados mais satisfatórios quanto à integração curricular e quanto à produção de objetos de aprendizagem por estudantes de Licenciatura em Computação. Como trabalhos futuros pretende-se aprimorar essa proposta como forma de dinamizar o seu processo e levar os estudantes ao êxito nas suas produções.

\section{Referências}

Andrade, J. M. S. Por uma docência institucionária: professores(as)-formadores(as) dos cursos de licenciatura do Instituto Federal Farroupilha e seus processos auto(trans)formativos. Programa de Pós-graduação em Educação. ( Tese de doutorado). UFSM, 2019.

Barboza, J. S. and Felicio, H. M. dos S. "Integração Curricular a partir da Análise de uma Disciplina de um Curso de Medicina” Rev. bras. educ. med., Brasília, v. 42, n. 3, p. 27-35, set. 2018. Disponível em <https://bit.ly/2xRprve>. Acesso em 17 jul. 2019.

Brasil. "Decreto no 5.296, de 2 de dezembro de 2004" Disponível em $<$ http://twixar.me/6rbK $>$ Acesso em: 08 abr. 2019.

Brasil. "Projeto Pedagógico do Curso de Licenciatura em Computação". Instituto Federal Farroupilha, Campus de Santo Augusto, 2014. Disponível em: <http://twixar.me/8rbK> Acesso em: 04 abr. 2019.

Brasil. Ministério da Educação. Conselho Nacional de Educação. Resolução CNE/CP 2, de 1 de julho de 2015: define as Diretrizes Curriculares Nacionais para a formação inicial em nível superior (cursos de licenciatura, cursos de formação pedagógica para graduados e cursos de segunda licenciatura) e para a formação continuada. Disponível em: $<$ http://portal.mec.gov.br/docman/agosto-2017-pdf/70431-res-cne-cp-002-03072015pdf/file>. Acesso em: 04 abr. 2019.

Cambraia, A. C. and Moraes, M.G. "Indissociabilidade entre ensino, pesquisa e extensão nas práticas como componente curricular na licenciatura em computação". In: CAMBRAIA, Adão Caron; ROSMANN, Márcia Adriana; SOARES, Renira Carla (Org.). Prática Profissional na educação tecnológica: concepções, experiências e dinâmicas investigativas. Passo Fundo: Méritos, 2015.

Cambraia, A. C.; Benvenutti, L. M. P. Relação Academia-Escola: Papel das Práticas Profissionais na Formação do Professor de Computação. Anais dos Workshops do Congresso 
VIII Congresso Brasileiro de Informática na Educação (CBIE 2019)

Anais dos Workshops do VIII Congresso Brasileiro de Informática na Educação (WCBIE 2019)

Brasileiro de Informática na Educação, [S.1.], p. 784, out. 2017. ISSN 2316-8889. Disponível em: <https://www.br-ie.org/pub/index.php/wcbie/article/view/7464>. Acesso em: 23 out. 2019.

Cambraia, A. C. Desenvolvimento profissional docente na recriação da prática curricular docente num curso de Licenciatura em Computação. Programa de Pós-graduação em Educação nas Ciências. ( Tese de doutorado). Unijuí, 2017.

Cambraia, A. C.; Zanon, L. B. Desenvolvimento profissional docente numa licenciatura: interlocuções sobre o projeto integrador. Rev. Bras. Educ., Rio de Janeiro, v. 23, e230043, 2018. Disponível em: 〈>. Acesso em 23 out. 2019.

Carneiro, M. L. F. and Silveira, M. S. "Objetos de Aprendizagem como elementos facilitadores na Educação a Distância” Educar em Revista. Curitiba, Edição Especial, nº 4 . Editora UFPR. 2014. Páginas 235-260.

Dose, E.M.C. “A importância do feedback na educação a distância” Revista on-line de Política e Gestão Educacional, v.21, n.3, p. 1565-1571, set./dez. 2017.

Felicio, H. M. S. “Integração Curricular: desafios de uma parceria interinstitucional” Revista eCurriculum, São Paulo, v. 13, n. 02 p. 214 - 231 abr./jun. 2015. Disponível em:

<http://revistas.pucsp.br/curriculum/article/download/13458/16968>. Acesso em: 17 jul 2019.

Filatro, A. "Design Instrucional na Prática" Person Education do Brasil. São Paulo: 2008. Mayer, R. "Multimedia Learning" The Psychology of Learning and Motivation. Vol 41. 2002.

55 páginas.

Jeffrey, D. C.; Assis, A. E. S. Q.; Grandin, L. O curso de licenciatura em pedagogia: uma análise das adequações normativas e curriculares. Revista Internacional de Educação Superior, V2, n.2, p. 291-310, mai./ago. 2016.

Pacheco, J. A. “Territorializar o currículo através de projectos integrados” In: PACHECO, J.

A. (org.). Políticas de Integração Curricular. p. 7 - 37. Porto: Editora Porto, 2000.

Souza, F.C.G. “Aperfeiçoamento do Quiz para a autoavaliação do conhecimento dos alunos em soldagem" Trabalho de Conclusão de curso. Universidade Federal de Uberlândia. Faculdade de Engenharia Mecânica. 2018. 32 páginas. Disponível em <https://bit.ly/2Gfe7xh> Acesso em 16 de jul. 2019.

Sweller, J., Merrienboer, J. J. G. Van and Paas, F. G. W. C. "Cognitive Architecture and Instructional Design”. Educational Psychology Review, Vol. 10, No. 3, 1998. 46 páginas.

Wiley, D. A. "Learning Object Design and Sequencing Theory" Thesis (Philosophy Course), Department Of Instructional Psychology And Technology, Brigham Young University, Provo, Utah, USA, 2000. 